\title{
CONCRETO TRANSLÚCIDO - LUZ NATURAL PARA AMBIENTES FECHADOS
}

\section{Translucent concrete - natural light for closed environments}

\author{
Sayonara Michelle Mesquita Paiva Souza ${ }^{1}$, Marineide Jussara Diniz ${ }^{2}$ \\ Recebido em 01 de junho de 2017; recebido para revisão em 14 de junho de 2017; aceito em 18 de julho de 2017; \\ disponivel on-line em 10 de agosto de 2017.
}

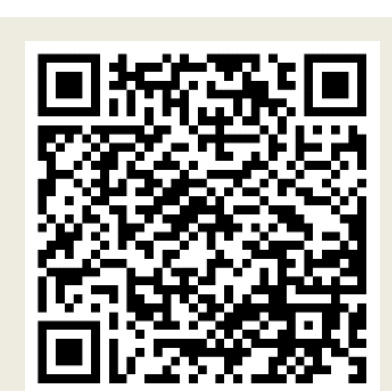

PALAVRAS CHAVE:

Concreto translúcido;

Fibra óptica;

Ambientes fechados;

Iluminação natural;

Construção civil.

RESUMO: O concreto por ter ampla utilização na construção civil, é constantemente objeto de pesquisas entre os estudiosos, sempre com o intuito de melhorar suas propriedades e aumentar seu uso nas edificações. O concreto é uma mistura de aglomerantes, agregados, aditivos e água. O concreto trouxe para a construção civil a possibilidade de projetar e executar as mais variadas formas, no entanto sempre foi um desafio para arquitetos e engenheiros a questão da iluminação nos ambientes fechados. Foi diante dessa dificuldade que surgiu um novo material no mercado, um concreto capaz de aliar as propriedades do concreto convencional com a iluminação natural, o Concreto Translúcido. O Concreto Translúcido é composto por concreto convencional e fibras ópticas, são essas fibras que permitem a passagem de luz através do concreto, conferindo assim um material favorável ao meio ambiente, tendo em vista que o consumo de energia pode ser reduzido. Este trabalho tem por objetivo mostrar as características desse novo material, suas vantagens e desvantagens e suas aplicações no Brasil e no mundo.

* Contato com o autor:

${ }^{1}$ e-mail: sayonara.michelle@hotmail.com ( S.M.M.P Souza )

Especialista em Engenharia de Instalações Prediais pelo Programa de Pós Graduação em Engenharia de Instalações Prediais - UNP.

${ }^{2}$ e-mail: marineide@ufersa.edu.br (M.J. Diniz)

Doutora, Professora do Departamento de Ciências Ambientais e Tecnológicas - UFERSA.
\end{abstract}

\section{INTRODUÇÃO}

Durante muito tempo utilizou-se o concreto para fins unicamente estruturais. No Brasil, no início do século $\mathrm{XX}$, o concreto armado popularizou-se com a arquitetura moderna sendo amplamente utilizado para dar formas a obras de arquitetos renomados como Oscar Niemeyer. Alguns arquitetos ousavam utilizar o concreto sem revestimento, deixando-o aparente. Porém, recentemente mais uma alternativa surgiu: o concreto translúcido.

O concreto translúcido, criado em 2001, foi desenvolvido e patenteado pelo arquiteto Húngaro Aron Losonczi, que incorporou fibra óptica à matriz cimentícia, sem prejuízo da resistência à compressão característica do concreto estrutural. A fibra óptica é um filamento de vidro, que também pode ser de material produzido com polímero, que tem alta capacidade de transmitir os raios de luz. As fibras ópticas são dispostas no bloco, paralelamente e com as extremidades expostas nas superfícies que ficarão aparentes, através das quais ocorrerá a transmissão de luz, proporcionado iluminação natural e economia de energia.

O objetivo deste trabalho é apresentar o concreto translúcido como produto a ser empregado em larga escala em áreas afins da construção; conhecer o processo de obtenção; expor as principais características do concreto translúcido e evidenciar o produto como um meio alternativo para preservação do meio ambiente, 
através da redução de luz artificial.

\section{METODOLOGIA DE PESQUISA}

O desenvolvimento do presente trabalho foi baseado em pesquisa exploratória sobre o tema proposto, proporcionando uma melhor compreensão a respeito de uma inovação tecnológica bastante interessante e importante, ressaltando suas características, vantagens e aplicações na construção civil. $O$ trabalho foi dividido em levantamento bibliográfico e redação do projeto e que ao final possibilitou o conhecimento a cerca de um material novo, que alia resistência, segurança e preocupação ambiental.

\section{REVISÃO DE LITERATURA}

\subsection{CONCRETO TRANSLÚCIDO}

Quando se fala em engenharia sustentável, logo se pensa na inserção de novos materiais aos processos. As pesquisas estão trazendo para os novos materiais funções e características antes inimagináveis para os produtos. Recentemente mais uma alternativa surgiu: o concreto translúcido, que é uma junção do concreto convencional com fibra óptica.

A fibra óptica é um meio de transmissão que utiliza a luz para transportar a informação através de uma rede de comunicação. Constitui-se em uma estrutura cilíndrica composta por material dielétrico, geralmente plástico ou vidro como mostra a Figura 1. A transmissão em fibra óptica é realizada pelo envio de um sinal de luz codificado, dentro do domínio de frequência do infravermelho, através de um cabo óptico (PROJETO DE REDES, 2010).

O feixe de luz, ao incidir na superfície do concreto, especificamente na fibra óptica, atravessa o material, ilumina o meio oposto e produz o efeito translúcido e dependendo da distância do objeto da superfície e do observador também é capaz de perceber suas cores.

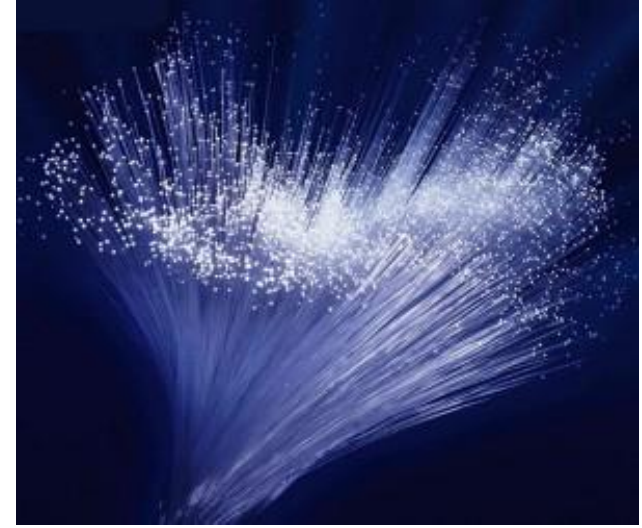

FIGURA 1: Fibra Óptica. FONTE: PEREIRA (2011).

A inovação é da empresa Litracon ${ }^{\circledR}$ e foi desenvolvido e patenteado pelo arquiteto húngaro Àron Lesonczi, o Transcon, o concreto translúcido, apresenta a resistência e a solidez do concreto convencional e ainda permite a passagem de luz como mostra a Figura 2. Tal propriedade Ihe confere o status de produto ecologicamente correto, já que proporciona economia de energia ao transformar o aspecto interior dos edifícios de concreto aproveitando melhor a luz solar. O concreto translúcido também é mais maleável e impermeável do que o tradicional. Essas características, aliadas à sua resistência, dificultam as chances de rachaduras e infiltrações (CONSTRUÇÃO CIVIL, 2012).

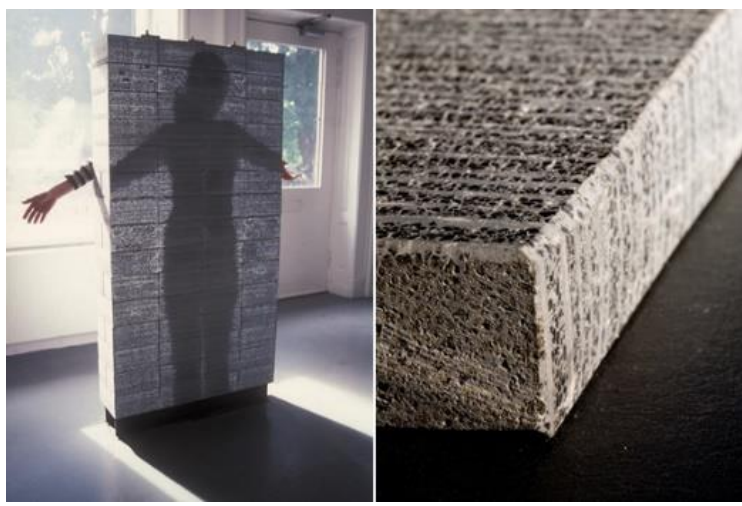

FIGURA 2 - Concreto Transmissor de Luz. FONTE: HIGUTI (2012).

\subsubsection{Processo de fabricação}

O concreto translúcido é um material compósito, composto por matriz (meio aglomerante, comumente formado por cimento e água) e elemento de reforço (agregados, como brita e areia), e por fibras óticas, podendo conter na 
mistura, aditivos, fibras, pigmentos e adições, sendo basicamente formado por $96 \%$ de concreto e $4 \%$ de fibra óptica (RIBEIRO, 2010). O processo de fabricação do concreto translúcido compreende as seguintes etapas:

- Adição de material moldável dentro da forma alongada, com paredes laterais e base como mostra a Figura 3;

- Disposição de uma camada de fibras, várias e paralelas, longitudinalmente, ao longo da fôrma, que pode ser de aço ou madeira;

- Submeter a fôrma à pressão mecânica e/ou vibração até que as fibras afundem na matriz até o nível desejado;

- Repetir a sequência de procedimentos até completar a altura prevista;

- O concreto passa do estado fresco para o estado endurecido no molde e resulta em peça sólida homogênea;

- Remoção da peça do molde;

- Corte dos blocos, a peça será cortada, no sentido transversal, em blocos, de forma que as extremidades das fibras fiquem visíveis nas laterais dos blocos e ao formar uma parede, fiquem expostas.

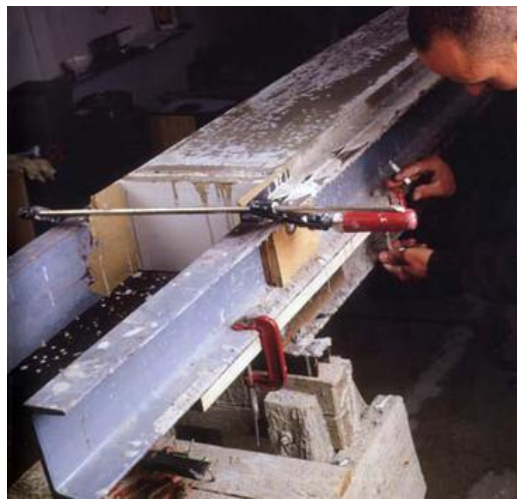

FIGURA 3: Molde concreto com fibra óptica. FONTE: RESTREPO (2013)

Dois centros de pesquisa no Brasil já conseguiram desenvolver o concreto translúcido, um é o Laboratório de Materiais de Construção da Universidade Estadual Vale do Acaraú, em Sobral, no Ceará, e o outro é o Laboratório de Tecnologia da Construção da Univates (Universidade do Vale do Taquari), em Lajeado, no Rio Grande do Sul. O objetivo dos pesquisadores brasileiros é conseguir reduzir o custo de fabricação do concreto translúcido, para que ele ganhe mercado, tendo em vista que o valor alto do concreto translúcido se deve ao fato de que ele utiliza fibras ópticas misturadas com concreto auto adensável (RESTREPO, 2013).

A diferença do processo brasileiro para o húngaro é que no país europeu ela já está sendo produzido industrialmente. 0 processo de fabricação brasileiro de um bloco de concreto translúcido com medidas de $9 \times 19 \times 29 \mathrm{~cm}$ compreende as seguintes etapas:

- São montadas fôrmas com fechamento em acrílico com furos executados a laser com $1 \mathrm{~mm}$ de diâmetro, espaçados em $1 \mathrm{~cm}$ como mostra a Figura 4;

- A fibra óptica é passada pelos furos do acrílico em uma única direção como mostra a Figura 5. Para confeccionar um bloco são utilizados cerca de $60 \mathrm{~m}$ de fibra óptica;

- Encher a fôrma com concreto auto adensável como mostra a Figura 6;

- Após concretada, a peça fica de dois a três dias em retração inicial para evitar a quebra dos cantos mais frágeis. Ele passa por um processo de cura e é submerso em água. O bloco pronto pode ser visto na Figura 7.

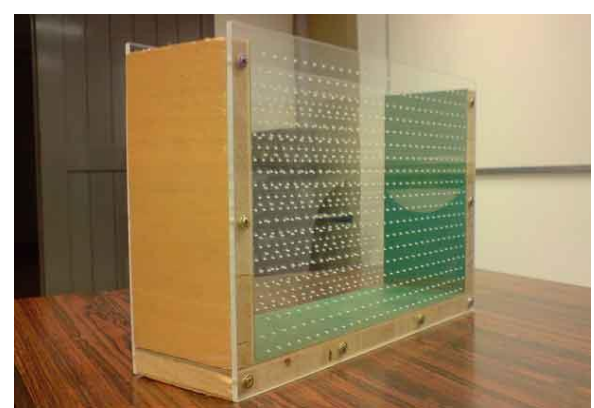

FIGURA 4: Fôrma usada para a fabricação do bloco de concreto translúcido.

FONTE: FARIA (2009).

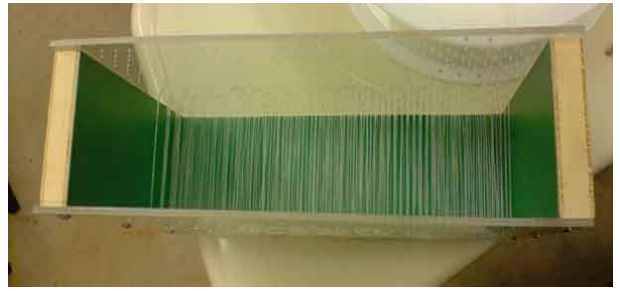

FIGURA 5: Fibras ópticas posicionadas na fôrma. FONTE: FARIA (2009). 


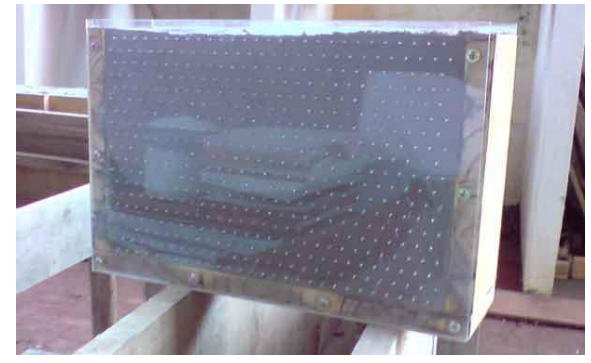

FIGURA 6: Fôrma concretada. FONTE: FARIA (2009).

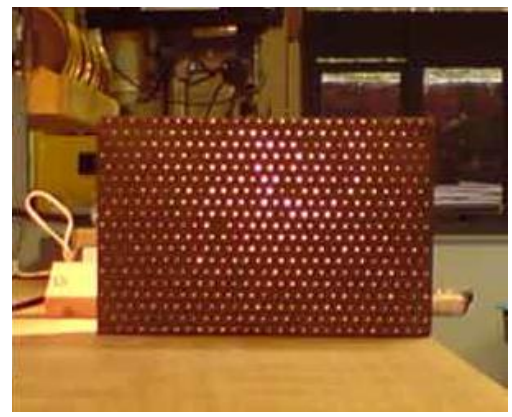

FIGURA 7: Bloco de concreto pronto. FONTE: FARIA (2009).

\subsubsection{Vantagens}

As vantagens do concreto translúcido superam as desvantagens (RESTREPO, 2013). As principais vantagens do concreto translúcido são:

- Capacidade de transmitir a luz, aproveitando melhor a luz solar;

- Mais maleável e impermeável graças à presença das fibras ópticas;

- Redução de luz artificial, diminuindo o consumo de energia;

- Apresenta pequena absorção de água;

- Redução da permeabilidade, e um peso em volume de $30 \%$ inferior a um concreto convencional.

\subsubsection{Desvantagens}

- Por ser um produto novo no mercado, seu custo de fabricação ainda é alto;

- Até agora, considerado apenas um produto de alvenaria de vedação, seu uso é exclusivo para decoração;

- Mão de obra mais especializada, o que aumenta o custo do produto.

\subsubsection{Aplicações do concreto translúcido}

3.1.4.1 Aplicações do concreto translúcido no mundo
Diversas são as aplicações do concreto translúcido no mundo, como mostram as Figuras 8, 9 e10.

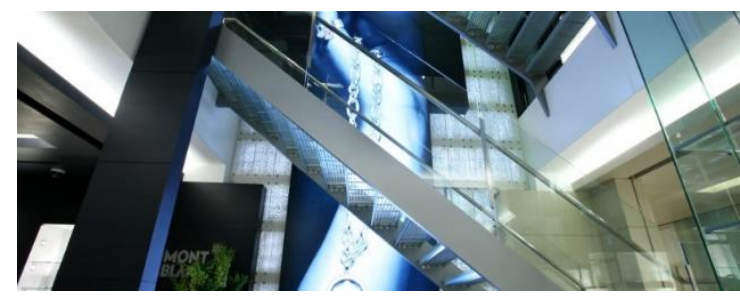

FIGURA 8: Boutique Montblanc no Japão. FONTE: LITRACON (2011).

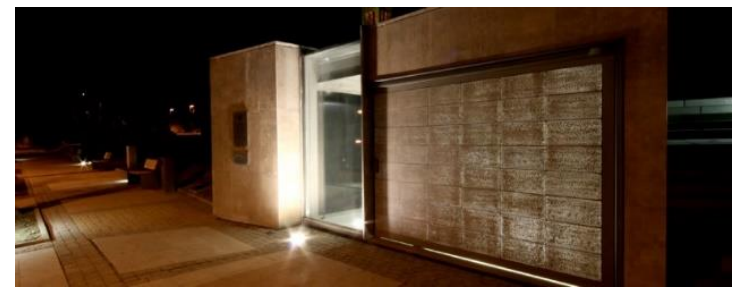

FIGURA 9: Museu Cella Septichora na Hungria. FONTE: LITRACON (2011).

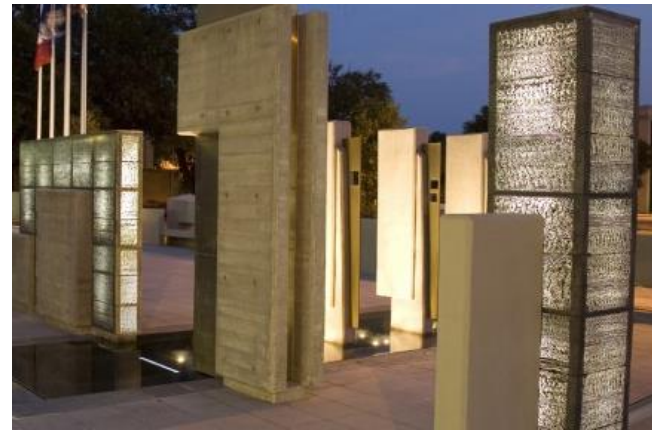

FIGURA 10: Memorial de Veteranos de Iberville Parish, em Louisiana, EUA.

FONTE: LITRACON (2011).

3.1.4.2 Aplicações do concreto translúcido no Brasil

Além dos dois centros que já conseguiram desenvolver o concreto translúcido no Brasil, surge à empresa Dosacon. A Dosacon (incubadora tecnológica da Univates) foi fundada desde o início de 2010, e que tem como finalidade o desenvolvimento de materiais e produtos para a industrialização civil a base de concreto (material composto por cimento, areia e fibra óptica), com ênfase na elaboração de produtos sustentáveis (RESTREPO, 2013). Além de blocos cinza, a empresa produz blocos com cimento branco e com a adição de pigmentos, conferindo diversas cores como mostra a Figura 11 (DOSACON, 2014). 


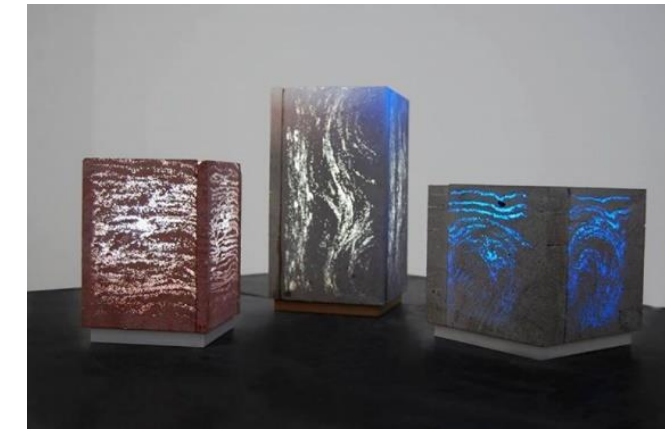

FIGURA 11 - Concreto Translúcido produzido pela Dosacon.

FONTE: DOSACON (2014)

\section{CONSIDERAÇÕES FINAIS}

O concreto por ser um dos materiais mais utilizados na construção civil, sempre terá seu espaço nos estudos e pesquisas desenvolvidos no Brasil e no Mundo. Por esse motivo, novos materiais vêm sendo estudados e lançados no mercado a todo tempo, com o objetivo de melhorar suas características e aumentar seu uso nas mais diversas obras civis. Um exemplo desse avanço nas melhorias das propriedades do concreto foi a criação do concreto translúcido, um material que trouxe para a construção civil a possibilidade de transmitir a luz natural para ambientes fechados. Essa característica do concreto translúcido é atribuída a adição de fibras ópticas ao concreto convencional.

O concreto translúcido chegou ao mercado com uma proposta de aliar técnica, qualidade e sustentabilidade, tendo em vista que a iluminação natural proporcionada por ele pode reduzir significativamente o consumo de energia. Apesar de todas as suas vantagens e importância para a construção civil e meio ambiente, o concreto translúcido ainda é pouco estudado e difundido no mercado nacional.

É preciso mais estudos e investimentos em novos produtos, novas tecnologias, principalmente quando se tem uma proposta de melhoria nas características técnicas aliado a conservação do meio ambiente.

\section{REFERÊNCIAS BIBLIOGRÁFICAS}

CONSTRUÇÃO CIVIL, 2012. Inovações no concreto -

Concreto Translúcido. Disponível em: https://construcaocivilpet.wordpress.com/2012/03/08/i novacoes-no-concreto-1-concreto-translucido/. Acesso em 16 dez, 2014.

DOSACON, 2014. Tijolo Translúcido. Disponível em: http://www.dosacon.com.br/produto_detalhe.php?cat= 3. Acesso em 20 dez., 2014.

FARIA, Renato. Alunos da Univates - RS reproduzem Concreto Translúcido (2009). Disponível em: http://piniweb.pini.com.br/construcao/tecnologiamateriais/alunos-da-univates-rs-reproduzem-concretotranslucido-153607-1.aspx. Acesso em 22 dez., 2014.

HIGUTI, André. Concreto Translúcido - Litracon (2012). Disponível em: http://arktetonix.com.br/2012/03/concreto-translucidolitracon/. Acesso em 19 dez., 2014.

LITRACON, 2011. Disponível em: http://www.litracon.hu. Acesso em 19 dez., 2014.

PEREIRA, Filipe. Fibra ótica chega aos 100 terabits por segundo (2011). Disponível em: http://dezinteressante.com/?p=7035. Acesso em 19 dez., 2014

PROJETO DE REDES, 2010. Fibra Óptica. Disponível em: http://www.projetoderedes.com.br/aulas/ugb_infraestr utura/UGB_aula3_Conceitos_de_Infraestrutura.pdf. Acesso em 20 dez., 2014.

RESTREPO, Laura Margarita Cadavid. Concreto Translúcido: Estudo Experimental sobre a Fabricação de Painéis de Concreto com Fibra Óptica e as suas Aplicações na Arquitetura. Dissertação do programa de pós-graduação em Arquitetura e Urbanismo da Universidade de Brasília, Brasília, 2013.

RIBEIRO, Raquel de Macedo. Concreto Aparente: Uma Contribuição para a Construção Sustentável. Monografia (Curso de Especialização em Construção Civil). Universidade Federal de Minas Gerais, Belo Horizonte, 2010.

TUTIKIAN, Bernardo Fonseca. Concreto Translúcido pode ir além da estética (2009). Disponível em: http://www.cimentoitambe.com.br/concretotranslucido-pode-ir-alem-da-estetica/. Acesso em 18 dez., 2014. 